\title{
The effect of life insurance settlement on insurance market and consumer welfare
}

\author{
Jimin Hong ${ }^{1, a}$ \\ ${ }^{a}$ Department of Statistics and Actuarial Science, Soongsil University, Korea
}

\begin{abstract}
This study investigates the effect of life settlement on the monopolistic insurance market. In particular, we consider liquidity cost, which is the cost incurred to the insurer to meet the request of surrender, and trading cost, which is the transaction cost of the policyholders for the settlement. We first show that the introduction of a life settlement can increase insurance demand and enhance consumer welfare even when the trading cost is higher than the liquidity cost. That is, even if the settlement market is less efficient than the insurance market, both insurance demand and consumer welfare can be increased. Second, the insurer's profit can also be increased when settlement is introduced because not only can the insurer save the liquidity cost but also the demand of insurance increases. Lastly, insurance demand does not always decrease when both costs increase. Depending on the population distribution over the liquidity risk, the demand of insurance can be increased or decreased.
\end{abstract}

Keywords: life settlement, liquidity cost, trading cost, insurance demand, surrender value

\section{Introduction}

A life insurance contract covers an accident such as the death of an insured, and in the event of the insured's death within the insurance period, the beneficiary will receive the indemnity (death benefit). However, the policyholder and the insured may not be the same person.

Although motivations to purchase life insurance vary, one of the main motivations is "bequest motive." In other words, policyholders intend to leave money to provide funds for an inheritance tax and living expenses for dependents. However, policyholders may lose their incentive to inherit over time since the insurance period is very long. In addition, policyholders may find difficulty to maintain insurance contract due to financial difficulties such as losing jobs and medical expenses. At this time, policyholders will choose to terminate the life insurance contract, and the insurance company will pay cash surrender value following a predetermined surrender schedule.

Surrender can be interpreted as the process of reselling the insurance policies back to the insurance company. However, policyholders cannot sell the insurance contract to any insurer other than the insurer from which they purchase the insurance. That is, in the process of surrender, the insurer has monopsony power. There is a widespread perception in the U.S. that the surrender value is generally low, with about 3 to 5 percent of the death benefit.

The low surrender value has contributed to the birth of a life settlement. Life settlement refers to a transaction in which the policyholders are allowed to sell their life insurance contract to a third-party investor, a so-called settlement provider. From the transaction, policyholders receive the settlement

\footnotetext{
${ }^{1}$ Department of Statistics and Actuarial Science, Soongsil University, 369, Sangdo-Ro, Dongjak-Gu, Seoul 06978, South Korea. E-mail: jmhong@ssu.ac.kr
}

Published 30 November 2020 / journal homepage: http://csam.or.kr

(c) 2020 The Korean Statistical Society, and Korean International Statistical Society. All rights reserved. 
price, whereas the investor receives the death benefit instead of paying a premium when policyholders die. Policyholders have an incentive to participate in such a transaction as long as the settlement price is higher than the surrender value. It is known that the correlation between death risk and financial market risk is nearly zero. Therefore, settlement investors can diversify their assets by incorporating life insurance into their portfolio. In fact, at the beginning of the settlement, investors obtain a return of between $8 \%$ and $12 \%$. However, as the life expectancy increases due to the rapid development of medical technology, investors had negative returns, resulting in a decrease in the settlement volume.

The life settlement market is small compared with the primary market, the life insurance market. According to Conning Research and Consulting (2011), only 1\% of all life insurance contracts are settled. Meanwhile, Magna Report (2018) estimates that only 1,250 of the approximately 500,000 life insurance contracts that are lapsed each year flow into the settlement market, with a settlement ratio of only about $0.25 \%$. This means that the life settlement market has growth potential. Magna Report (2018) also estimates the size of the settlement market to be 38 billion dollars in 2018 based on the face value.

Some economic studies address the positive effect of the life settlement. For instance, Doherty and Singer (2003) point out that the introduction of life settlement may enhance consumer welfare because it reduces the insurer's monopsony power when the policyholder surrenders. Given that surrender can be interpreted as the reselling of an insurance contract, the policyholder cannot sell her insurance contract to any insures other than the insurer from which she purchases the insurance. Hong and Seog (2018) consider a heterogeneous liquidity risk of policyholders, and thus, the introduction of life settlement may increase the benefit of the consumer. On the other hand, Seog and Hong (2019) consider the liquidity risks of both the insurer and policyholder. They consider the liquidity costs of both the insurer and policyholder. The introduction of life settlement increases the efficiency of the insurer and policyholder in that both can save the liquidity costs. Using the data of 7,164 policyholders, Januário and Naik (2013) empirically find that when settlement is allowed, surrender value increased by up to four times. Fang and $\mathrm{Wu}$ (2020) state that life settlement corrects the biased belief of policyholders over their liquidity and mortality risk. Furthermore, under the assumption that the positive liquidity cost is incurred only to the insurer, Hong (2019) finds that the increase in welfare comes from both the increase in insurance demand and the cost reduction of surrender due to settlement.

Meanwhile, other studies point out the negative effect of life settlement. Daily et al. (2008) and Fang and Kung (2010) show that the introduction of life settlement deteriorates consumer welfare because the insurance premium would be increased. Moreover, Gatzert et al. (2008) argue that the introduction of settlement may lower the insurer's profit because the insurers lose surrender profit. However, other studies show that the introduction of life settlement enhances consumer welfare.

In this study, we consider a monopolistic insurer to investigate the effect of settlement on the insurance market. Unlike Hong and Seog (2018), who consider the insurance and settlement market as a perfect market, and Hong (2019), who conjectures that only liquidity cost of the insurer for surrender exists, we consider a trading cost of life settlement as well as liquidity cost of surrender. Both costs decrease consumer welfare while affecting the insurance market through different mechanisms. This assumption is similar to that of Seog and Hong (2019). However, this study differs from the study of Seog and Hong (2019) in two ways. First, Seog and Hong (2019) set the model in which policyholders choose to surrender for cash needs even when the benefit from surrender is less than that from keeping insurance in the long term perspective, whereas we set the model in which the policyholders choose to surrender with liquidity risk since the utility from surrender is greater than that from keeping insurance. Note that Seog and Hong (2019) assume that policyholders face a kind of liquidity constraint. 
As a result, we show that policyholders with higher liquidity risk than target liquidity risk purchase life insurance, whereas Seog and Hong (2019) state that policyholders with low liquidity risk than target liquidity risk purchase life insurance. Who purchases insurance is an empirical question. Second, while Seog and Hong (2019) only focus on uniform population distribution, we investigate the effect of several population distribution on insurance demand. We analyze the effect of an increasing or decreasing linear population distribution function as well as uniform distribution.

Our findings are summarized as follows. First, the introduction of settlement can increase insurance demand and consumer welfare even when the settlement market is less efficient than the insurance market. Second, the insurer's profit increases when settlement is allowed. This result comes from the fact that not only the insurer can save the liquidity cost but also the settlement may increase insurance demand. Lastly, insurance demand does not always decrease when both costs increase. The insurer may respond in a way that the increase or decrease in demand makes the most of her profit, depending on the population distribution over liquidity risk. These results show that the life settlement market can be complementary to the insurance market, not a competitor.

The remainder of this paper is organized as follows. In Section 2, we describe the model assumptions. In Section 3, we propose a model to depict an equilibrium in the insurance market when settlement is not allowed. In Section 4, we investigate the change in equilibrium when settlement is allowed. In Section 5, we identify the results using numerical examples, and in Section 6, we conclude the paper.

\section{The model descriptions}

As aforementioned, we extend the model of Hong and Seog (2018) into the model with the cost of insurer and settlement investors. Similar to Hong and Seog (2018), we consider a monopolistic insurer in a two-period model. $t=0, t=1$, and $t=2$ denote time, and $\rho$ denotes the time discount factor. A potential policyholder purchases life insurance at time 0 and pays insurance premium $Q$. At time 1 , the following events occur in sequence. First, liquidity shock with the size of $y$ occurs with probability $q$. Liquidity risk refers to the probability that the policyholder needs urgent cash. Second, the policyholder chooses to surrender the policy and receives the surrender value $S, S \geq 0$. Note that negative surrender value is not feasible in reality. If a settlement is allowed, the policyholder can choose between surrender and settlement. At time 2, the death event occurs with probability $p_{1}$. We suppose that death benefit $D$ is fixed. The income in each period is denoted by $W_{0}, W_{1}$, and $W_{2}$, respectively.

Let us suppose that the settlement market is competitive. Hong and Seog (2018) examine whether the settlement market exists, whereas we only focus on the case wherein the settlement market exists. In addition, Hong and Seog (2018) suppose that the settlement market is perfect, and thus, any trading cost for settlement does not exist. By contrast, we suppose that the unit trading cost exists, which is denoted by $e$. Consequently, the settlement price is equal to the difference between the fair value of death benefit and the trading cost: $(1-e) \rho p_{1} D$. Figure 1 presents the timeline.

Meanwhile, Hong and Seog (2018) assumed that no additional cost is incurred for the insurer to meet the request of policyholder's surrender. However, in general, the expected loss or expense that occurs when the insurer sells the investment assets can be regarded as the liquidity cost. The cost can be interpreted as an opportunity cost arising from an insurer's inability to invest in assets with higher returns. This is because the insurer needs to invest in assets with higher liquidity to satisfy the sudden needs of surrender even if the expected return is low. The cost can also be interpreted as an external financing cost if borrowing is required to pay the surrender value for policyholders. $c$ denotes the 


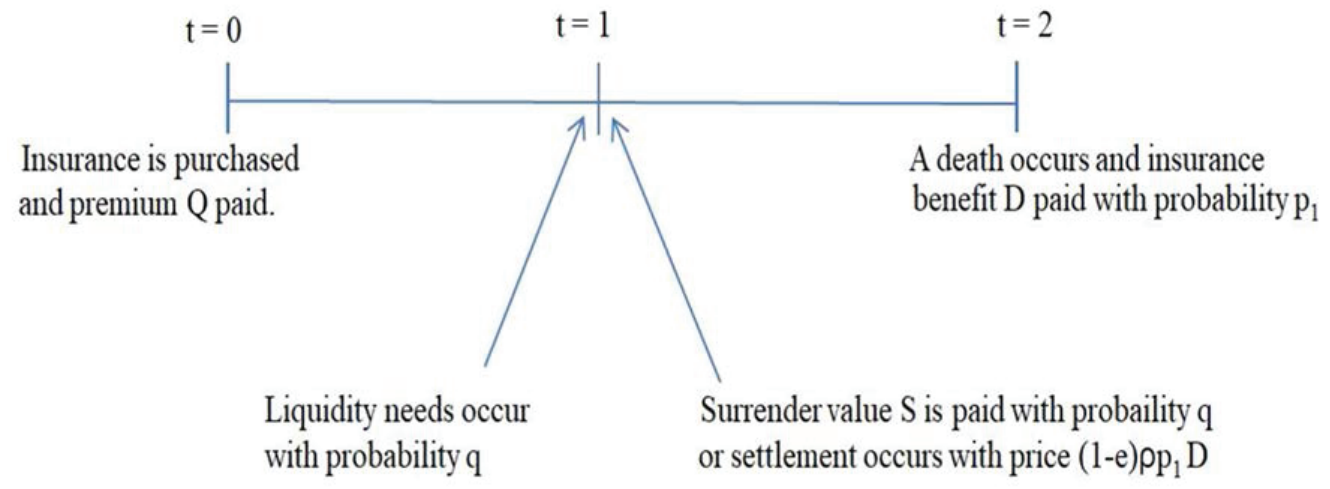

Figure 1: The time line of model.

liquidity cost, which is the cost per unit, where $0 \leq c \leq 1$. Meanwhile, $c S$ denotes the total liquidity cost for surrender.

Insurance premium consists of the sum of the premiums in consideration of the expected value of payments (e.g., surrender value and death benefit), liquidity cost, and rent additionally charged by the insurer. Let us first consider an insurance premium in which the insurer can discriminate the policyholder against her liquidity risk as a benchmark case. If the rent is denoted as $R$, then the insurance premium for policyholder $i$ with liquidity risk $q_{i}$ when the settlement is not allowed is as follows:

$$
Q_{i}=\rho q_{i}(1+c) S+\rho^{2}\left(1-q_{i}\right) p_{1} D+R .
$$

However, as we discussed above, discrimination against liquidity risk is not allowed. Therefore, the insurer targets a specific liquidity risk $q^{T}$ to maximize the insurer's profit:

$$
Q=\rho q^{T}(1+c) S+\rho^{2}\left(1-q^{T}\right) p_{1} D+R .
$$

Note that the insurance premium $Q$ is the same for all policyholders.

We suppose that policyholders have heterogeneous liquidity risk but the same death risk. The population of potential policyholders is distributed over the liquidity risk $q$. The population density function (pdf) and the cumulative distribution function (cdf) of $q$ are denoted by $f(q)$ and $F(q)$, respectively. It is assumed that the insurer cannot offer different life insurance contracts to policyholders based on their liquidity risk.

Following Daily et al. (2008), Fang and Kung (2010), and Hong and Seog (2018), we divided the policyholder's utility into two parts. First, if the policyholder is alive and her consumption is $W$, the utility is denoted as $u(W)$. The policyholder's utility becomes zero if she dies. Second, if she dies and her dependent inherits $W$, the utility becomes $v(W)$, where $v(\cdot)$ denotes the utility incorporated for the dependent, reflecting a bequest motive. Both utility functions are strictly increasing concave and twice differentiable: $u^{\prime}(W)>0, u^{\prime \prime}(W)<0$ and $v^{\prime}(W)>0, v^{\prime \prime}(W)<0$. For simplicity, we assume that $v(0)=0$.

The policyholder purchases insurance only when the expected utility with insurance $\left(\mathrm{EU}_{1}\right)$ is greater than or equal to the utility without insurance $\left(\mathrm{EU}_{0}\right)$. To focus on the pure effect of settlement, we only discuss the case wherein the policyholder chooses to surrender (or settle) when she faces 
liquidity risk. That is, the utility to surrender is greater than the utility to maintain the insurance: $u\left(W_{1}-y+S\right)>u\left(w_{1}-y\right)+\rho p_{1} v(D)$. The expected utilities for $q_{i}$ are as follows:

$$
\begin{aligned}
\mathrm{EU}_{0}= & u\left(W_{0}\right)+\rho q_{i} u\left(W_{1}-y\right)+\rho\left(1-q_{i}\right) u\left(W_{1}\right)+\rho^{2}\left(1-p_{1}\right) u\left(W_{2}\right), \\
\mathrm{EU}_{1}= & u\left(W_{0}-Q\right)+\rho q_{i} \max \left\{u\left(W_{1}-y+S\right), u\left(w_{1}-y\right)+\rho p_{1} v(D)\right\}+\rho\left(1-q_{i}\right) u\left(W_{1}\right) \\
& +\rho^{2}\left(1-p_{1}\right) u\left(W_{2}\right)+\rho^{2}\left(1-q_{i}\right) p_{1} v(D), \\
= & u\left(W_{0}-Q\right)+\rho q_{i} u\left(W_{1}-y+S\right)+\rho\left(1-q_{i}\right) u\left(W_{1}\right)+\rho^{2}\left(1-p_{1}\right) u\left(W_{2}\right)+\rho^{2}\left(1-q_{i}\right) p_{1} v(D) .
\end{aligned}
$$

From (2.3) and (2.4), we can derive the net benefit of $q_{i}$ purchasing insurance is as follows:

$$
\begin{aligned}
\mathrm{NB}\left(q_{i}\right) & =\mathrm{EU}_{1}-\mathrm{EU}_{0} \\
& =u\left(W_{0}-Q\right)+\rho q_{i} u\left(W_{1}-y+S\right)+\rho^{2}\left(1-q_{i}\right) p_{1} v(D)-u\left(W_{0}\right)-\rho q_{i} u\left(W_{1}-y\right) .
\end{aligned}
$$

The insurer sets the insurance premium to extract the net benefit of policyholders to the maximum. However, only those who have nonnegative net benefit will purchase insurance. Let us denote the marginal policyholder (liquidity risk $q_{T}$ ) with zero net profit as a target policyholder: $\operatorname{NB}\left(q^{T}\right)=0$. From this observation, the following lemma is proposed.

Lemma 1. Potential policyholders who have higher liquidity risk than target liquidity risk purchase insurance.

Proof: A Policyholder with $q^{\prime}$ purchases insurance when the following condition holds:

$$
\begin{aligned}
0= & \mathrm{NB}\left(q^{T}\right) \leq \mathrm{NB}\left(q^{\prime}\right) \\
\Rightarrow & u\left(W_{0}-Q\right)+\rho q^{T} u\left(W_{1}-y+S\right)+\rho^{2}\left(1-q_{T}\right) p_{1} v(D)-u\left(W_{0}\right)-\rho q^{T} u\left(W_{1}-y\right) \\
& \leq u\left(W_{0}-Q\right)+\rho q^{\prime} u\left(W_{1}-y+S\right)+\rho^{2}\left(1-q^{\prime}\right) p_{1} v(D)-u\left(W_{0}\right)-\rho q^{\prime} u\left(W_{1}-y\right) .
\end{aligned}
$$

By rearranging (2.6), we obtain the following:

$$
\left(q^{\prime}-q^{T}\right) \rho\left[u\left(W_{1}-y+S\right)-\rho p_{1} v(D)-u(W-y)\right] \geq 0 .
$$

Since $u\left(W_{1}-y+S\right)>u\left(w_{1}-y\right)+\rho p_{1} v(D)$, we have $q^{\prime} \geq q^{T}$.

Lemma 1 shows that potential policyholders with higher liquidity risk than target liquidity risk obtain net benefit such that they prefer to purchase insurance. Lemma 1 also implies that the insurer cannot fully extract benefit from the policyholder, allowing policyholders to enjoy positive net benefits.

\section{The basic model: when settlement is not allowed}

In this section, we investigate the optimal insurance contract and welfare. Recall that the monopolistic insurer determines insurance contract, such as premium, surrender value, target liquidity risk, and rent, to maximize the insurer's expected profit, given death benefit. The insurer's profit maximization problem is as follows:

$$
\begin{aligned}
\max _{S, R, q^{T}} \pi\left(S, R, q^{T}\right) & =Q\left(1-F\left(q^{T}\right)\right)-\rho(1+c) S \int_{q^{T}}^{1} q f(q) d q-\rho^{2} p_{1} D \int_{q^{T}}^{1}(1-q) f(q) d q \\
& =\left[\rho(1+c) S-\rho^{2} p_{1} D\right]\left[q^{T}\left(1-F\left(q^{T}\right)\right)-\int_{q^{T}}^{1} q f(q) d q\right]+R\left[1-F\left(q^{T}\right)\right]
\end{aligned}
$$




$$
\begin{array}{ll}
\text { s.t. } & u\left(W_{0}-Q\right)+\rho q^{T} u\left(W_{1}-y+S\right)+\rho^{2}\left(1-q^{T}\right) p_{1} v(D)-u\left(W_{0}\right)-\rho q^{T} u\left(W_{1}-y\right)=0 \\
& Q=\rho q^{T}(1+c) S+\rho^{2}\left(1-q^{T}\right) p_{1} D+R .
\end{array}
$$

Using (3.1)-(3.3), we obtain the following Lagrangian with multiplier $\lambda$ :

$$
\begin{aligned}
L= & {\left[\rho(1+c) S-\rho^{2} p_{1} D\right]\left[q^{T}\left(1-F\left(q^{T}\right)\right)-\int_{q^{T}}^{1} q f(q) d q\right]+R\left[1-F\left(q^{T}\right)\right] } \\
& +\lambda\left[u\left(W_{0}-Q\right)+\rho q^{T} u\left(W_{1}-y+S\right)+\rho^{2}\left(1-q^{T}\right) p_{1} v(D)-u\left(W_{0}\right)-\rho q^{T} u\left(W_{1}-y\right)\right] .
\end{aligned}
$$

The first order conditions at the optimum are as follows:

$$
\begin{aligned}
L_{s}= & \rho(1+c)\left[q^{T}\left(1-F\left(q^{T}\right)\right)-\int_{q^{T}}^{1} q f(q) d q\right]+\lambda \rho q^{T}\left[-(1+c) u^{\prime}\left(W_{0}-Q\right)+u^{\prime}\left(W_{1}-y+S\right)\right]=0, \\
L_{q^{T}}= & {\left[\rho(1+c) S-\rho^{2} p_{1} D\right]\left[1-F\left(q^{T}\right)\right]-R f\left(q^{T}\right) } \\
& +\lambda \rho\left[\left(-(1+c) S+\rho p_{1} D\right) u^{\prime}\left(W_{0}-Q\right)+u\left(W_{1}-y+S\right)-\rho p_{1} v(D)-u\left(W_{1}-y\right)\right]=0 . \\
L_{R}= & {\left[1-F\left(q^{T}\right)\right]-\lambda u^{\prime}\left(W_{0}-Q\right)=0 } \\
L_{\lambda}= & u\left(W_{0}-Q\right)+\rho q^{T} u\left(W_{1}-y+S\right)+\rho^{2}\left(1-q^{T}\right) p_{1} v(D)-u\left(W_{0}\right)-\rho q^{T} u\left(W_{1}-y\right)=0 .
\end{aligned}
$$

Let us denote the optimal surrender value, target liquidity risk, rent and insurance premium as $S^{*}, q^{*}, R^{*}$ and $Q^{*}$, respectively, at which $Q^{*}=\rho q^{*}(1+c) S^{*}+\rho^{2}\left(1-q^{*}\right) p_{1} D+R^{*}$. From the above expressions, we have following Lemma 2.

Lemma 2. The optimal insurance contract when settlement is not allowed satisfies following conditions.

(a) $(1+c) \int_{q^{*}}^{1} q f(q) d q=q^{*}\left[1-F\left(q^{*}\right)\right] \frac{u^{\prime}\left(W_{1}-y+S^{*}\right)}{u^{\prime}\left(W_{0}-Q^{*}\right)}$,

(b) $R^{*} f\left(q^{*}\right)=\frac{1-F\left(q^{*}\right)}{u^{\prime}\left(W_{0}-Q^{*}\right)} \rho\left[u\left(W_{1}-y+S^{*}\right)-\rho p_{1} v(D)-u\left(W_{1}-y\right)\right]$,

(c) $u\left(W_{0}-Q^{*}\right)+\rho q^{*} u\left(W_{1}-y+S^{*}\right)+\rho^{2}\left(1-q^{*}\right) p_{1} v(D)-u\left(W_{0}\right)-\rho q^{*} u\left(W_{1}-y\right)=0$.

Proof: From (3.6), we have $\lambda=\left(1-F\left(q^{*}\right)\right) / u^{\prime}\left(W_{0}-Q^{*}\right)$. By substituting this term into (3.4) and (3.5), we obtain the above expressions.

Lemma 2 restates the conditions of Hong (2019). These conditions imply that the optimal surrender value (target liquidity risk and rent) is determined at the point where the marginal revenue is equal to the marginal cost of the insurer. The liquidity cost of insurer reduces the efficiency, and thus, the insurer may increase or decrease the optimal target liquidity risk and net benefit of policyholders. Lastly, we define consumer welfare $(\mathrm{CW})$ as the sum of the net benefit of policyholders who purchase the insurance: $\int_{q^{*}}^{1} N B(q) f(q) d q$. 


\section{The model: when settlement is allowed}

As pointed above, the transaction cost such as tax can be incurred in the settlement market (Seog and Hong, 2019). Similarly, we also consider a unit trading cost of settlement, $e$. If a settlement is allowed, then the insurer's profit maximization problem is changed as follows:

$$
\begin{aligned}
& \max _{R_{s}, q_{s}^{T}} \pi\left(R_{s}, q_{s}^{T}\right)=Q_{s}\left(1-F\left(q_{s}^{T}\right)\right)-\rho^{2} p_{1} D\left[1-F\left(q_{s}^{T}\right)\right]=R_{s}\left[1-F\left(q_{s}^{T}\right)\right], \\
& \text { s.t. } u\left(W_{0}-Q\right)+\rho q_{s}^{T} u\left(W_{1}-y+(1-e) \rho p_{1} D\right)+\rho^{2}\left(1-q_{s}^{T}\right) p_{1} v(D)-u\left(W_{0}\right)-\rho q_{s}^{T} u\left(W_{1}-y\right)=0 \\
& \quad Q_{s}=\rho^{2} p_{1} D+R_{s} .
\end{aligned}
$$

Moreover, the insurer faces additional constraint for surrender value because the trading cost is incurred to policyholders. The expected payment for the settlement investor is $\rho p_{1} D$, and thus, the settlement price is regarded as $(1-e) \rho p_{1} D$ while the settlement investors receive the death benefit. In this case, the insurer sets a new surrender value less than the settlement price when settlement is allowed. Note that the insurer does not have an incentive to offer a higher value than the settlement price because of the liquidity cost. That is, the optimal surrender value is virtually zero for the insurer. In addition, the interaction between cost saving and an increase in payment affects the insurer's decision to target liquidity risk and rent. The insurer newly targets liquidity risk $q_{s}^{T}$ and rent $R_{s}$ as in (4.1) and (4.3). Let us denote the insurance premium with settlement as $Q_{s}$. We then obtain Lagrangian as follows:

$$
\begin{aligned}
L= & R_{s}\left[1-F\left(q_{s}^{T}\right)\right] \\
& +\lambda_{s}\left[u\left(W_{0}-Q_{s}\right)+\rho q_{s}^{T} u\left(W_{1}-y+(1-e) \rho p_{1} D\right)+\rho^{2}\left(1-q_{s}^{T}\right) p_{1} v(D)-u\left(W_{0}\right)-\rho q_{s}^{T} u\left(W_{1}-y\right)\right] .
\end{aligned}
$$

The first order conditions are:

$$
\begin{aligned}
& L_{q_{s}^{T}}=-R_{s} f\left(q_{s}^{T}\right)+\lambda_{s} \rho\left[u\left(W_{1}-y+(1-e) \rho p_{1} D\right)-\rho p_{1} v(D)-u\left(W_{1}-y\right)\right]=0, \\
& L_{R_{s}}=\left[1-F\left(q_{s}^{T}\right)\right]-\lambda_{s} u^{\prime}\left(W_{0}-Q_{s}\right)=0, \\
& L_{\lambda_{s}}=u\left(W_{0}-Q_{s}\right)+\rho q_{s}^{T} u\left(W_{1}-y+(1-e) \rho p_{1} D\right)+\rho^{2}\left(1-q_{s}^{T}\right) p_{1} v(D)-u\left(W_{0}\right)-\rho q_{s}^{T} u\left(W_{1}-y\right)=0 .
\end{aligned}
$$

The optimal target liquidity risk, rent and insurance premium are denoted by $q_{s}^{*}, R_{s}^{*}$, and $Q_{s}^{*}$, respectively. By rearranging the above conditions, we have following Proposition 1.

Proposition 1. The optimal insurance contract when settlement is allowed satisfies the following conditions

(a) $R_{s} f\left(q_{s}^{*}\right)=\frac{1-F\left(q_{s}^{*}\right)}{u^{\prime}\left(W_{0}-Q_{s}^{*}\right)} \rho\left[u\left(W_{1}-y+(1-e) \rho p_{1} D\right)-\rho p_{1} v(D)-u\left(W_{1}-y\right)\right]$,

(b) $u\left(W_{0}-Q_{s}^{*}\right)+\rho q_{s}^{*} u\left(W_{1}-y+(1-e) \rho p_{1} D\right)+\rho^{2}\left(1-q_{s}^{*}\right) p_{1} v(D)-u\left(W_{0}\right)-\rho q_{s}^{*} u\left(W_{1}-y\right)=0$.

Proof: From (4.6), we obtain $\lambda_{s}=\left[1-F\left(q_{s}^{*}\right)\right] / u^{\prime}\left(W_{0}-Q_{s}\right)$. By substituting this term into (4.5), we obtain the above expressions.

Similar to Lemma 2, Proposition 1 states the insurer determines the optimal target liquidity risk (rent) where the marginal revenue equals the marginal cost. The settlement market leads the insurer 
to choose the contract $\left(S_{s}^{*}=(1-e) \rho p_{1} D, R_{s}^{*}, q_{s}^{*}\right)$, instead of the original optimal insurance contract $\left(S^{*}, R^{*}, q^{*}\right)$. In this case, consumer welfare with settlement $\left(\mathrm{CW}_{s}\right)$ is $\int_{q_{s}^{*}}^{1} N B(q) f(q) d q$.

Hong and Seog (2018) show the profit of the insurer always decreases when settlement is allowed, whereas our proposition shows that the profit may or may not increase due to the liquidity cost saving. Meanwhile, the trading cost reduces the net benefit of policyholders and consequently affects the demand of insurance. Hong and Seog (2018) assume that both liquidity and trading costs are equally zero. However, the result is not preserved in the case in which liquidity and trading costs are equally positive. Even when the efficiency of surrender is greater than settlement, that is, the transaction cost is greater than the liquidity cost, settlement can enhance consumer welfare. The demand of insurance and the insurer's profit can be increased. However, it is not easy to find an explicit condition to increase welfare, demand, and profit since in this study, the optimization problem with settlement is not a reduced form of the problem without settlement like Hong and Seog (2018) or Seog and Hong (2019). Thus, we identify the results using a numerical example. The effects of the settlement are summarized in Proposition 2.

Proposition 2. Let us suppose that the efficiency of settlement is less than that of surrender. The followings are the effects of settlement on the insurance market:

(a) The profit of the insurer can be increased.

(b) The demand of insurance and consumer welfare can be increased.

Proof: See the following numerical example.

The increase in costs implies low efficiency, and the costs may distort the optimal decision of both the insurer and policyholders. Thus, as the costs increase, consumer welfare may decrease. However, the direction of change in insurance demand is unclear since the change depends on the population distribution. This result is presented in the following proposition.

Proposition 3. As both liquidity and trading costs increase, insurance demand can be either increased or decreased depending on the shape of population distribution.

Proof: See the following numerical example.

\section{Numerical examples}

In this section, using numerical examples, we show the change in the insurance contract and welfare as the costs change. In addition, Hong and Seog (2018), Seog and Hong (2019), and Hong (2019) only focused on the case in which the population distribution is uniform distribution. We analyze the effect of several distributions on insurance contract and welfare through numerical examples.

Let us first suppose that the population of policyholders over liquidity risk has a uniform distribution in $[0,1]$. In addition, we assume that the utility functions exhibit constant absolute risk aversion (CARA utility functions): $u(W)=10-100 \exp (-a W)$ and $v(W)=9-9 \exp (-a W)$ with risk aversion $a=0.3$. The endowments are: $W_{0}=W_{1}=14, d=16, p_{1}=0.2, \rho=1 / 1.03$, and $y=14$.

We first identify the case wherein the target liquidity risk decreases (i.e., insurance demand increases) with settlement when the liquidity and trading costs are the same. Even though the insurance premium increases with settlement, the demand and consumer welfare can be increased. In the case where the population distribution follows a uniform distribution, the insurer reacts to decrease the 
Table 1: Change in insurance contract and welfare as liquidity and trading costs change when the population distribution $f(q)$ is $2 q$ uniform distribution on $[0,1]$

\begin{tabular}{|c|c|c|c|c|c|c|c|c|c|c|}
\hline \multirow{6}{*}{$\begin{array}{l}\text { Settlement } \\
\text { is not } \\
\text { allowed }\end{array}$} & $\begin{array}{l}\text { Liquidity } \\
\text { cost }\end{array}$ & 0 & 0.01 & 0.015 & 0.02 & 0.025 & 0.03 & 0.035 & 0.04 & 0.045 \\
\hline & $S^{*}$ & 2.8585 & 2.8381 & 2.8280 & 2.8181 & 2.8081 & 2.7983 & 2.7885 & 2.7787 & 2.7691 \\
\hline & $q^{*}$ & 0.3261 & 0.3264 & 0.3266 & 0.3268 & 0.3270 & 0.3271 & 0.3273 & 0.3275 & 0.3277 \\
\hline & $Q^{*}$ & 8.7759 & 8.7658 & 8.7608 & 8.7507 & 8.7507 & 8.7457 & 8.7407 & 8.7357 & 8.7307 \\
\hline & $\pi^{*}$ & 3.9892 & 3.9831 & 3.9801 & 3.9770 & 3.9740 & 3.9709 & 3.9678 & 3.9648 & 3.9617 \\
\hline & CW & 54.2197 & 53.9676 & 53.8422 & 53.7174 & 53.5931 & 53.4692 & 53.3458 & 53.2229 & 53.1005 \\
\hline \multirow{6}{*}{$\begin{array}{l}\text { Settlement } \\
\text { is } \\
\text { allowed }\end{array}$} & $\begin{array}{c}\text { Trading } \\
\text { cost }\end{array}$ & 0 & 0.01 & 0.015 & 0.02 & 0.025 & 0.03 & 0.035 & 0.04 & 0.045 \\
\hline & $\rho p_{1} D$ & 3.1068 & 3.1068 & 3.1068 & 3.1068 & 3.1068 & 3.1068 & 3.1068 & 3.1068 & 3.1068 \\
\hline & $q_{s}^{*}$ & 0.3253 & 0.3257 & 0.3259 & 0.3261 & 0.3263 & 0.3265 & 0.3267 & 0.3269 & 0.3271 \\
\hline & $Q_{s}^{*}$ & 8.9197 & 8.9052 & 8.8978 & 8.8904 & 8.8829 & 8.8754 & 8.8678 & 8.8601 & 8.8524 \\
\hline & $\pi_{s}^{*}$ & 3.9830 & 3.9710 & 3.9649 & 3.9587 & 3.9525 & 3.9463 & 3.9401 & 3.9337 & 3.9274 \\
\hline & $\mathrm{CW}_{s}$ & 57.1765 & 56.8185 & 56.6383 & 56.4572 & 56.2753 & 56.0925 & 55.9089 & 55.7244 & 55.5390 \\
\hline
\end{tabular}

Table 1 presents the change in insurance contract and welfare as liquidity and trading costs change. In this case, $S^{I}$ which satisfies $u\left(W_{1}-y+S^{I}\right)=u\left(w_{1}-y\right)+\rho p_{1} v(D)$ is 0.0583 , which is greater than optimal surrender value in all cases. Thus, policyholders always choose to surrender (or settle) when they face liquidity needs. As the liquidity cost increases, the optimal surrender value and insurance demand without settlement decreases. Similarly, when settlement is allowed, insurance demand also decreases as the trading cost increases. There exists the case that insurance demand and consumer welfare increase even if the trading cost is greater than the liquidity cost. For example, if the liquidity cost is zero (0.02) and the trading cost is $0.015(0.035)$, both insurance demand and consumer welfare with settlement are greater than those without settlement. The initial values are as follows: $W_{0}=W_{1}=14, D=16, p_{1}=0.2$, and $y=14$. The utility functions are: $u(W)=10-100 \exp (-a W)$ and $v(W)=9-9 \exp (-a W)$ where a denotes risk aversion. In this example, $a=0.3$.

surrender value and insurance demand as the liquidity cost increases. In particular, the insurer lowers surrender value to save liquidity costs, which lowers the policyholder's net benefit, thereby reducing the demand of insurance. As the trading cost increases, the net benefit also decreases, which in turn decreases insurance demand.

In this case, we observe that even if the trading cost is greater than the liquidity cost, the demand of insurance and consumer welfare can be increased as well. This result implies that the settlement and insurance markets can be complementary rather than competitive with each other. All these observations are summarized in Table 1.

Second, we suppose that the population of policyholders over liquidity risk follows that $f(q)=2 q$ in $[0,1]$. This distribution function is somewhat extreme, but it means that there are more policyholders exposed to higher liquidity risk than those exposed to lower liquidity risk. We also assume that the utility functions exhibit CARA utility functions. The endowments and utility functions are the same as those when the population is uniformly distributed.

In this case, we also observe that insurance demand and consumer welfare can be increased despite the increase in insurance premium when settlement is allowed. As the costs increase, consumer welfare and insurer's profit decrease. The results are presented in Table 2.

Lastly, we suppose that the population of policyholders over liquidity risk follows that $f(q)=$ $-2 q+2$ in $[0,1]$. This distribution implies that there are fewer policyholders exposed to higher liquidity risk are than those exposed to lower liquidity risk. We also assume that the utility functions exhibit CARA utility functions. The utility functions are the same as those when the population is uniformly distributed. The endowments are: $W_{0}=W_{1}=18, D=16, p_{1}=0.2, \rho=1 / 1.03$, and $y=14$. Note that wealth is greater than those under the uniform distribution case. This is because if the wealth is 14 under this linear decreasing population distribution, all policyholders do not choose to surrender or settle even when they face the liquidity risk. 
Table 2: Change in insurance contract and welfare as liquidity and trading costs change when the population distribution $f(q)$ is $2 q$ uniform distribution on $[0,1]$

\begin{tabular}{|c|c|c|c|c|c|c|c|c|c|c|}
\hline \multirow{6}{*}{$\begin{array}{l}\text { Settlement } \\
\text { is not } \\
\text { allowed }\end{array}$} & $\begin{array}{c}\text { Liquidity } \\
\text { cost }\end{array}$ & 0 & 0.01 & 0.015 & 0.02 & 0.025 & 0.03 & 0.035 & 0.04 & 0.045 \\
\hline & $S^{*}$ & 2.6595 & 2.6403 & 2.6308 & 2.6213 & 2.6120 & 2.6027 & 2.5934 & 2.5842 & 2.5751 \\
\hline & $q^{*}$ & 0.4210 & 0.4213 & 0.4214 & 0.4216 & 0.4217 & 0.4218 & 0.4220 & 0.4221 & 0.4223 \\
\hline & $Q^{*}$ & 9.4165 & 9.4043 & 9.3983 & 9.3923 & 9.3862 & 9.3802 & 9.3742 & 9.3682 & 9.3622 \\
\hline & $\pi^{*}$ & 3.9291 & 3.9235 & 3.9207 & 3.9179 & 3.9151 & 3.9123 & 3.9095 & 3.9067 & 3.9039 \\
\hline & CW & 37.8539 & 37.6668 & 37.5738 & 37.4812 & 37.3890 & 37.2972 & 37.2057 & 37.1147 & 37.0240 \\
\hline \multirow{6}{*}{$\begin{array}{l}\text { Settlement } \\
\text { is } \\
\text { allowed }\end{array}$} & $\begin{array}{c}\text { Trading } \\
\text { cost }\end{array}$ & 0 & 0.01 & 0.015 & 0.02 & 0.025 & 0.03 & 0.035 & 0.04 & 0.045 \\
\hline & $\rho p_{1} D$ & 3.1068 & 3.1068 & 3.1068 & 3.1068 & 3.1068 & 3.1068 & 3.1068 & 3.1068 & 3.1068 \\
\hline & $q_{s}^{*}$ & 0.4207 & 0.4210 & 0.4211 & 0.4213 & 0.4214 & 0.4216 & 0.4217 & 0.4219 & 0.4220 \\
\hline & $Q_{s}^{*}$ & 9.7062 & 9.6899 & 9.6817 & 9.6734 & 9.6650 & 9.6566 & 9.6481 & 9.6395 & 9.6309 \\
\hline & $\pi_{s}^{*}$ & 3.8754 & 3.8640 & 3.8583 & 3.8525 & 3.8467 & 3.8408 & 3.8349 & 3.8289 & 3.8229 \\
\hline & $\mathrm{CW}_{s}$ & 41.9213 & 41.6561 & 41.5226 & 41.3884 & 41.2536 & 41.1182 & 40.9822 & 40.8455 & 40.7082 \\
\hline
\end{tabular}

Table 2 presents the optimal insurance contract and consumer welfare as liquidity and trading costs change. In this case, $S^{I}$ which satisfies $u\left(W_{1}-y+S^{I}\right)=u\left(w_{1}-y\right)+\rho p_{1} v(D)$ is 0.0583 , which is greater than optimal surrender value in all cases. Thus, policyholders choose to surrender (or settle) when they face liquidity needs. As the liquidity cost increases, the optimal surrender value and insurance demand without settlement decrease. Similarly, when settlement is allowed, insurance demand decreases as the trading cost increases. There exists the case that insurance demand and consumer welfare increase even if the trading cost is greater than the liquidity cost. For example, if the liquidity cost is $0.01(0.035)$ and the trading cost is $0.015(0.04)$, both insurance demand and consumer welfare with settlement are greater than those without settlement. The initial values are as follows: $W_{0}=W_{1}=14, D=16, p_{1}=0.2$, and $y=14$. The utility functions are: $u(W)=10-100 \exp (-a W)$ and $v(W)=9-9 \exp (-a W)$ where a denotes risk aversion. In this example, $a=0.3$.

Table 3: Change in insurance contract and welfare as liquidity and trading costs change when the population distribution $f(q)$ is $-2 q+2$ on $[0,1]$

\begin{tabular}{|c|c|c|c|c|c|c|c|c|c|c|}
\hline \multirow{6}{*}{$\begin{array}{l}\text { Settlement } \\
\text { is not } \\
\text { allowed }\end{array}$} & $\begin{array}{l}\text { Liquidity } \\
\text { cost }\end{array}$ & 0 & 0.01 & 0.015 & 0.02 & 0.025 & 0.03 & 0.035 & 0.04 & 0.045 \\
\hline & $S^{*}$ & 2.8958 & 2.8724 & 2.8608 & 2.8493 & 2.8378 & 2.8264 & 2.8151 & 2.8039 & 2.7927 \\
\hline & $q^{*}$ & 0.1580 & 0.1579 & 0.1579 & 0.1579 & 0.1579 & 0.1578 & 0.1578 & 0.1578 & 0.1577 \\
\hline & $Q^{*}$ & 7.7002 & 7.6896 & 7.6843 & 7.6790 & 7.6737 & 7.6684 & 7.6631 & 7.6578 & 7.6525 \\
\hline & $\pi^{*}$ & 4.0119 & 4.0071 & 4.0046 & 4.0022 & 3.9998 & 3.9973 & 3.9949 & 3.9924 & 3.9900 \\
\hline & $\mathrm{CW}$ & 15.2929 & 15.2065 & 15.1635 & 15.1206 & 15.0778 & 15.0351 & 14.9925 & 14.9500 & 14.9077 \\
\hline \multirow{6}{*}{$\begin{array}{c}\text { Settlement } \\
\text { is } \\
\text { allowed }\end{array}$} & $\begin{array}{c}\text { Trading } \\
\text { cost }\end{array}$ & 0 & 0.01 & 0.015 & 0.02 & 0.025 & 0.03 & 0.035 & 0.04 & 0.045 \\
\hline & $\rho p_{1} D$ & 3.1068 & 3.1068 & 3.1068 & 3.1068 & 3.1068 & 3.1068 & 3.1068 & 3.1068 & 3.1068 \\
\hline & $q_{s}^{*}$ & 0.1596 & 0.1595 & 0.1594 & 0.1594 & 0.1594 & 0.1593 & 0.1593 & 0.1592 & 0.1592 \\
\hline & $Q_{s}^{*}$ & 7.8040 & 7.7909 & 7.7843 & 7.7777 & 7.7710 & 7.7642 & 7.7574 & 7.7506 & 7.7437 \\
\hline & $\pi_{s}^{*}$ & 4.0238 & 4.0132 & 4.0078 & 4.0024 & 3.9970 & 3.9915 & 3.9859 & 3.9804 & 3.9748 \\
\hline & $\mathrm{CW}_{s}$ & 16.0453 & 15.9375 & 15.8832 & 15.8287 & 15.7739 & 15.7189 & 15.6635 & 15.6080 & 15.5522 \\
\hline
\end{tabular}

Table 3 presents the optimal insurance contract and consumer welfare as liquidity and trading costs change. In this case, $S^{I}$ which satisfies $u\left(W_{1}-y+S^{I}\right)=u\left(w_{1}-y\right)+\rho p_{1} v(D)$ is 0.1976 , which is greater than optimal surrender value in all cases. Thus, policyholders choose to surrender (or settle) when they face liquidity needs. As the liquidity cost increases, without settlement, the optimal surrender value decreases and insurance demand increases. When settlement is allowed, insurance demand also decreases as the trading cost increases. The initial values are as follows: $W_{0}=W_{1}=18, D=16$, $p_{1}=0.2$, and $y=14$. The utility functions are: $u(W)=10-100 \exp (-a W)$ and $v(W)=9-9 \exp (-a W)$ where a denotes risk aversion. In this example, $a=0.3$.

In this case, the profit of insurer increases when settlement is allowed. Consumer welfare can also be increased, but this result should be interpreted carefully. The decrease in insurance demand and the increase in consumer welfare indicate that the benefit of settlement is concentrated only on the policyholders with high liquidity risk, which is a relatively small portion of the total population. 
Therefore, in this case, problems of equity can arise.

In addition, as both the liquidity and trading costs increase, the insurer reacts to increase the insurance demand. This result reveals that the increase in costs does not work in one direction alone in insurance demand.

\section{Conclusions}

This study investigates the effect of life settlement on the insurance market when the liquidity and the trading costs are incurred. The liquidity cost is the cost incurred to the insurer to meet the request of surrender, whereas the trading cost is the transaction cost of settlement for the policyholders. We show that even when the trading cost is higher than the liquidity cost, the introduction of settlement can increase insurance demand and consumer welfare. The monopolistic insurer can either increase or decrease insurance demand depending on the population distribution over the liquidity risk of policyholders. The insurer's profit can also be increased when settlement is introduced. These results show that the settlement market can be complementary to the insurance market rather than a competitor.

\section{References}

Conning Research and Consulting (2011). Life settlements: An Asset Class Resets, Strategy Study Series.

Daily G, Hendel I, and Lizzeri A (2008). Does the secondary life insurance market threaten dynamic insurance?, American Economic Review, 98, 151-156.

Doherty NA and Singer HJ (2003). The benefits of a secondary market for life insurance policies, Real Property, Probate and Trust Journal, 38, 449-478.

Fang $\mathrm{H}$ and Kung E (2010). How does the life settlement affect the primary life insurance market? (Working Paper), Department of Economics of Duke University.

Fang $\mathrm{H}$ and $\mathrm{Wu} \mathrm{Z}$ (2020). Life insurance and life settlement markets with overconfident policyholders, Journal of Economic Theory, 189, 105093.

Gatzert N, Hoermann G, and Schmeiser H (2009). The impact of the secondary market on life insurers' surrender profits, Journal of Risk and Insurance, 76, 887-908.

Hong J (2019). The effect of life insurance securitization on consumer welfare and efficiency: focusing on life settlement, Journal of Risk Management, 30, 1-29.

Hong J and Seog SH (2018). Life insurance settlement and the monopolistic insurance market, Insurance: Mathematics and Economics, 81, 36-50.

Januário AV and Naik NY (2013). Empirical investigation of life settlements: the secondary market for life insurance policies, Social Science Research Network, Available from: http://dx.doi.org/ $10.2139 /$ ssrn.2278299

Magna Report (2018). Life Settlement Industry Report 2018.

Seog SH and Hong J (2019). The efficiency effects of life settlement on the life insurance market, Pacific-Basin Finance Journal, 56, 395-412. 